\title{
Comparison of Warming Efficiency of Greenhouse Solar Dryer with Four Distinct Design Implementations
}

\author{
Mrigank Bhushan \\ M.Tech Scholar \\ Department of Mechanical Engineering \\ Corporate Institute of Science and Technology \\ Bhopal, Madhya Pradesh, India \\ mrigank1bhushan@gmail.com
}

\author{
Prof. Ashish Murchikar \\ Head of Department \\ Department of Mechanical Engineering \\ Corporate Institute of Science and Technology \\ Bhopal, Madhya Pradesh, India
}

\begin{abstract}
Drying is a technique for transferring warmth from a source to a product while also removing moisture from the product in a limited space. When using sun drying, the heat required for drying is primarily provided by solar energy. In this paper we have discussed about the fundamentals of different types of green house solar dryer, and to develop new design of solar dryer that would maximize warming efficiency. The main goal of this research is to run a computational fluid dynamics analysis on a previous model to analyze the influence of the highest warming within the greenhouse solar dryer.
\end{abstract}

Keywords: Solar dryer, Greenhouse solar dryer, Solar Energy, Direct Solar Dryer, Indirect Solar Dryer.

\section{INTRODUCTION}

Crops, veggies, and fruits are dried in solar dryers to remove excess extra water. The solar dryer is constructed of readily available and inexpensive materials such as cement, galvanised iron, brick, and hardboard. Transparent solitary and double-layered sheets wrap the dryer's topmost layer. To capture radiation from the sun, the inside area is painted black. The inside temperature of the box is raised because it is insulated. The openings at the top of the container allow air to circulate.

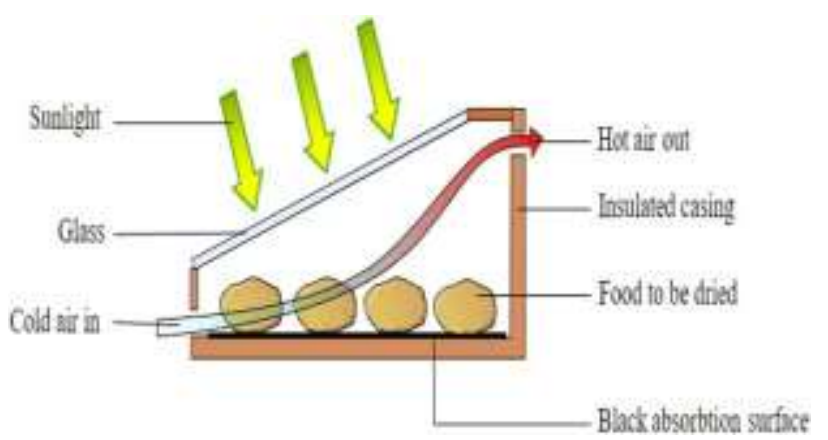

Figure 1. Solar Dryer
The excess water from the fruits, vegetables, and crops positioned in racks within the box is removed by the natural circulation procedure as the inside air warms. Fresh air is drawn in through a forcible draught method to fill the void, and the cycle is continued, as can be seen in figure above.

Solar energy is a fantastic way to meet our electricity requirements. Solar photovoltaics (photovoltaic cells) are solar panels that can straightforwardly convert sunlight into electricity. This light can be captured by photovoltaic cells and stored in a battery that can be refueled as needed. These could be used for a number of purposes. The dehydrated or dried material is exposed to open air in direct solar dryers. They have a dark absorbent surface that absorbs sunlight and converts it to heat. The substance to be dehydrated is positioned directly on the structure to be dried. These dryers can have a protection, glass lids, and/or ventilation slits to boost productivity.

Dryers are classified as either fossil fuel dryers (also known as conventional dryers) or solar powered dryers depending on their heaters. Reducing the heat dryers are energized by fossil fuels or solar panels, so although high-temperature dryers require fossil fuels.

\section{LITERATURE REVIEW}

D. Jagadeesh at el. (2020) [1]This study investigates how to select the best greenhouse drier from an array of choices. Every one of the six types of solar greenhouse dryers is designed to have a capacity of 30 cubic feet. The different forms are parabola, quonset, modified quonset, pyramid, igloo, and tropical.The inner heating rate of the greenhouse dryer is in the following sequence, from decreasing order, all through the summer season: Quonset, Tropical, Pyramid, Parabel, Modified Quonset, and Igloo. In the warmer months, the Quonset can generate 64 percent further warm air than the atmosphere, compared to 57 percent for the tropics, 56 
percent for the pyramid, 55 percent for the parabola and modified quonset, and 53 percent for the igloo. The challenging tropical variant produces $7 \%$ more temperature in the warmer months and 5\% more in the cold season than that of the quonset type.Because it produces a peak value of $72^{\circ} \mathrm{C}$ in the warmer months and $66^{\circ} \mathrm{C}$ in the cold season, the Quonset Shape is the perfect shape for a greenhouse solar drier.

Masnaji R. Nukulwar\&Vinod B. Tungikar (2020) [2]In the drying procedure, wood and fossil fuels are frequently used. This strategy, on the other hand, is expensive and potentially damaging to the environment, that is bad for the climate. Fossil fuels are in short supply around the world. The much more significant developments in solar dryer technology are summarized in this article. Some solar dryers use a heat accumulator to increase drying performance and effectiveness when the sun isn't shining. To compensate for variations in sunlight, some solar dryers have established solar thermal memory. To assess the solar dryer's efficacy, the researchers used metrics such as moisture mitigation, dehumidification rate, and different degrees of efficiency. No financial impact was realised due to the high initial cost, long payback period, and temporary use of solar dryers. Then why does using such a solar dryer end up saving fossil fuels for drying, but it also increases efficiency in terms of flavour and colour, according to the research. It also has no adverse effects on the environment.Solar dryers, as a consequence, are ideal for food preservation in rural areas. Agricultural workers and new investigators may benefit from this discovery as they work to establish a new type of solar product dryer.

Lakshmi DVN, Muthukumar P \&Nayak PK (2020) [3]This study looks at the performance of two active horizontal solar dryers, the blended mode (case I) and the indirect solar dryer (case II), both of which are used in a latent heat energy storage system to dry piper nigrum (black pepper). The moisture removal time in both case scenarios was 14 and 23 hours, respectively, to meet the target water content of 0.14 (d.b.) by 3.46. (d.b.). Throughout this time, it took 59 hours to dry during the day in the sun (case III). The dryers generated in cases I and II ended up saving 76 percent and 60 percent of the drying time, respectively, when compared to example III. Solar dryers that have been developed have a better financial return.Solar dryers that have been developed have a better financial return. As can be seen, Case I has a $20 \%$ higher overall dryer effectiveness than Case 2. Fresh and dried specimens were tested for quality and proximity, along with antioxidants, in all 3 scenarios. In case I, the carbohydrate and protein rates were increased than for the other two cases. The antioxidant content of the dried samples in instances I and III was 45.69 mol TE / g sample and 23.25 mol TE / g sample, respectively. When compared to the other two cases, Case III's test specimens had a high carbon content.

V.P. Sethi\&MankaranDhiman (2020) [4]A solar organic matter hybrid greenhouse drier (HGCD) will be illustrated, that also runs for 24 hours at a constant drying temperature of $62{ }^{\circ} \mathrm{C}$ using solar energy and bioenergy temperature. The longitudinal space (distance) among 2 consecutive planes is maximised for selected widths of $30^{\circ}, 35^{\circ}, 40^{\circ}, 45^{\circ}$, and $50^{\circ} \mathrm{N}$. Global solar radiation and heat models have been proposed to guesstimate the accessibility of solar radiation and the HGCD (Thged) chamber ambient temperature. The compelled draught straw bale burner (FDPSBC) is linked to the internet of fuel gas heat transfer pipes (FGHTPN) finished installing in the HGCD to keep a steady temperature in the Thged.The biomass heating load demand was guesstimated using an established heat transfer model (forced convection and radiant heat). The designed thermal model predicted a Thged of $26^{\circ} \mathrm{C}$ to $38^{\circ} \mathrm{C}$, that also equivalent to a thermal load of 4 to $6.5 \mathrm{~kW}$, if the air temperature in the Climate of india of Ludhiana $\left(30^{\circ} \mathrm{N}\right)$ remained among $10^{\circ}$ $\mathrm{C}$ and $18^{\circ} \mathrm{C}$. The heat transfer model provided extra heat of $26.2 \mathrm{~kW}$ and $13.4 \mathrm{~kW}$ at night temperatures of $-5^{\circ} \mathrm{C}$ and 10 ${ }^{\circ} \mathrm{C}$, respectively, by fully combusting $80 \mathrm{~kg}$ and $40 \mathrm{~kg}$ of straw shovel biomass per hour.

\section{Akhilesh Singh, Jahar Sarkar \&RashmiRekhaSahoo}

(2020) [5] The purpose of the research is to develop and test the proposed type of closed-loop infrared convection solar heat pump drier for banana chips. The four specific operating mechanisms of the system that are especially in comparison are simple thermal pump drying, infrared heat pump drying, solar heat pump drying, and solar infrared heat pump drying. Various energy and exegetical effectiveness performance measures are examined with respect to merchandise drying period and humidity concentration.Including an air velocity of $0.8 \mathrm{~m} / \mathrm{s}$ approaching the solar dryer, the banana chips are processed to remove 83.8 percent to 11.5 percent moisture in all modes of operation. Photovoltaic heat pump dryers have the highest energy efficiency $(58.5 \%)$ and are the most environmentally friendly ( 24 percent ). The solitary heat pump solar dryer has the best performance coefficient. The average moisture removal rate of the solar infrared heat pump drier is the highest $(1.1618 \mathrm{~kg} / \mathrm{h})$, while the solitary heat pump dryer is the least.

ZakariaAlimohammadi at el. (2020) [6] The purpose of this research was seeing how the category of liquid impacted the thermal power of a parabolic solar collector (PTSC). The modelling was used to predict temperature changes in the reception tube and storage tank using Computaion Fluid Dynamics. The tests were conducted at a circulation rate of $0.025 \mathrm{~kg} / \mathrm{s}$. For performance testing, nanofluid (Al2O3, 4\%), 
engine oil (10W40), glycerin, and water have been used. The solar dryer's drying procedure was factored into the equation while drying apple slices about a thickness of 5 mm.Nanofluids, oil, and glycerin all enhanced the dryer's overall effectiveness by $9.7 \%, 20.2$ percent, and 12.4 percent, respectively, once comparison with water. Comparative analysis of simulation model and destined results, the Computational fluid dynamic method can accurately assess the effectiveness of the PTSC with various working fluids. Various PCM-supported working fluids had no influence on the quality of dried apples.

Adnan Sozen at el. (2020) [7]The development of clean and sustainable energy is a necessity for emerging countries. Solar energy is a widely known renewable source of energy that can produce both electricity and heat. Solar thermal implementations could be used for a wide range of procedures, which include area heating and drying. In this research project, two low-cost, simplified-structure solar fan heating systems were developed and made. The first category of heating element is a vacuous tube heater. The 2 nd heating element has the same common functionalities as the previous one, with the exception that the circulation channel has been enlarged with iron strings to boost the thermal transfer area. To reference numerical results of simulated model, the gridmodified tubular heating element was created utilizing Ansys Fluent software. The two heating systems were connected in a drying room, and drying experiments were done with three different mass air circulations $(0.014,0.011$, and $0.009 \mathrm{~kg} / \mathrm{s})$. An iron mesh modified solar heater had the best immediate thermal performance of 74.71 percent. The improvement of thermal performance of tubular by up to $11 \%$ by modifying the network is observed. A customizable photovoltaic dryer with iron grids achieved the highest average energy conservation attributes of the dryers, with $50.85 \%$. The SAH tubular layout has been seen as as encouraging in aspects of renewable hot air generation owing to its simplicity and costeffective fabrication. It is made of sheet metal and has no casing or insulating substance.

Saloni Spall \&V.P. Sethi (2020) [8]An advanced frontloading MRT (Multi-Rack Tray) solar powered cabinet dryer including an optimal angle reflective north wall (RNW) is introduced, that uses a reflected portion of radiation from the sun for effective drying, especially during winter whenever a traditional dryer doesn't really operate better in higher latitudes $(>30>\mathrm{N})$. A reconfigured worldwide sun radiation detector model is provided to evaluate the influence of RNW on its achievement. A thermal model is also built through using Modified Euler methodology with experimental verification for the chamber air temperature (Tch) and the culture surface temperature (Tc) at the Ludhiana climate (30, $56^{\circ} \mathrm{N}$ ) in India.In the cold season, using RNW improves the absorption of radiation by 37.58 percent, 31.57 percent, and 23.24 percent at $30^{\circ}, 40^{\circ}$, and $50^{\circ}$ north latitudes, respectively. The daily average efficiency (mean) with RNW seemed to be $5 \%$ and 4.35 percent higher in free and forced convection methods, respectively, than that when there was really no RNW. Once RNW was being used in free or forced convective heat transfer, Tch was reported to be greater by 4$7^{\circ} \mathrm{C}$ and $2-5^{\circ} \mathrm{C}$, respectively, than when RNW was not utilized. In free and forced convection modes, the ultimate drying time for carrots was diminished by $20 \%$ and $15 \%$, respectively.

Y. Mohana at el. (2020) [9]This research will focus on providing a comprehensive document on emerging dryer designining features as well as other essential components, as well as a summary of the numerous implementations for several foods. Countless significant developments, complexities, and limitations in incorporating large-scale solar food drying are also discussed in terms of innovation, energy worries, and other socio - economic status concerns. As a consequence, this overview provides valuable data regarding the present state of solar dryers, trying to assist in the expansion of this environmentally friendly and long-term food science and technology.

\section{METHODOLOGY}

Drying is a methodology for transferring warmth from the a source to an item while also removing extra water from the item in a limited space. While utilizing sun drying, the heat required for drying is primarily provided by solar energy. To circulate air to the dryer, you can use forcible or environmental convection. In an organic greenhouse solar dryer, the fluid is relocated by buoyant forces caused by density variations induced by temperature modifications in the liquid. In a greenhouse, the sun dryer is a closed structure with transparent walls and roof.The dimensional requirements for the greenhouse solar dryer are $1.2 \mathrm{x} 1.2 \mathrm{x}$ $1.5 \mathrm{~m}, 0.65 \mathrm{~m}$ for the depth of the wall surface from the base, $0.01 \mathrm{~m}$ for the entry area on all four edges, and $0.15 \mathrm{M}$ for the fan intake diameter mass flow rate. A polycarbonate plate suspended from the ceiling allows infrared radiation to enter the dryer. The radiation model uses a site in Bhopal with longitude and latitude of $23.25^{\circ} \mathrm{N}$ and $77.33^{\circ} \mathrm{W}$.

Food moisture material is measured on a wet basis, that is, the mass of moisture per unit mass of wet grain, and presented as

$$
\begin{gathered}
X=\frac{\text { massofwater }}{\text { massofwater }+ \text { massofdrysolids }} \\
X=\frac{m_{w}}{m_{w}+m_{c}^{D}}
\end{gathered}
$$

[\% wb] or [kg water / kg wet grain] 
The alternative measure refers to the measurement on a dry basis -

$$
\begin{gathered}
X=\frac{\text { massofwater }}{\text { massofdrysolids }} \\
X=\frac{m_{w}}{m_{c}^{D}}
\end{gathered}
$$

Moisture content $\mathrm{x}$ [percent wb] is commonly found in food composition charts, so although moisture $X$ [percent $\mathrm{db}$ ] is more commonly found in sorption isotherms and drying curves.

The equation can be used to determine the rate of water loss from wet grain during drying.

$$
m_{w}=m_{c}{ }^{D}\left[\frac{\left(X_{i}-X_{e}\right)}{\left(100-X_{e}\right)}\right] k g
$$

Applying initial moisture content $\mathrm{xi}$ and the finished or equilibrium moisture levels $\mathrm{xe}$ in [percent wb]; or employing moisture in [percent $\mathrm{db}$ ]

$$
\text { Drying rate }=\left[\begin{array}{l}
\frac{(\text { initial weight })-\text { final weight }}{\text { time interwal }} \\
/ \text { sec or } \mathrm{kg} / \mathrm{h}
\end{array}\right] \mathrm{g}
$$

Dryingefficiency

$$
=\frac{\text { Heatutilizedformoistureremoval }}{\text { Heatavailableformoistureremoval }}
$$

moisturecontentonwetbasis

$$
=\left[\frac{\text { weightof weter }}{\text { weightofwater }+ \text { weightofdrymatter }}\right] \times 100
$$

$$
M C_{w b}=\left[\frac{W t_{w}}{W t_{w}+W t_{d m}}\right] \times 100
$$

moisturecontentondrybasis

$$
\begin{aligned}
= & {\left[\frac{\text { weightofweter }}{\text { weightofdrymatter }}\right] \times 100 } \\
M C_{d b} & =\left[\frac{W t_{w}}{W t_{d m}}\right] \times 100
\end{aligned}
$$

Dryer efficiency: $\eta_{d}=\frac{m L}{I_{c} A t}$

\section{Computational Fluid Dynamics Analysis of Greenhouse Solar Dryer}

Computational fluid dynamics is the use of computer based simulation to analyse systems involving fluid circulation and exchange of heat. The technique is extremely powerful, and it can be used in both industry based and nonindustrial settings. The current study uses Ansys Fluent to perform a computerised fluid dynamics assessment for solar greenhouse dryers at various mass flow rates. Definitive equations including the continuity equation, momentum equation, and energy equations are being used to conduct this computational analysis. CFD is a branch of computer science that uses software algorithms to solve fluid flow problems. All Computational Fluid Dynamics packages have sophisticated user interfaces for approaching problem parameters and trying to navigate the results to make accessing the performance of your solution easier. As a result, three key aspects are used to overcome computational fluid dynamics problems.

\section{RESULT AND DISCUSSION}

With the same boundary conditions, the results of the base paper and the current work were evaluated by comparing. The highest temperature at mid plane for mass flow rate of $0.025 \mathrm{~kg} / \mathrm{sec}$ is seen that for both the base paper and the current work, with an 8.34 percentage change due to the specified site as can be seen in figure no. (a) \& (b) (b). Following the validation of the base model, a new greenhouse solar dryer design was proposed and tested using computational fluid dynamics to improve heat transfer. Because it was discovered in the base paper that a $100 \mathrm{~m}$ thickness of polycarbonatesheet gives better results in achieving the maximum temperature in the Greenhouse solar dryer, the thickness of polycarbonatesheet in the current work was set at $100 \mathrm{~m}$ for all designs.

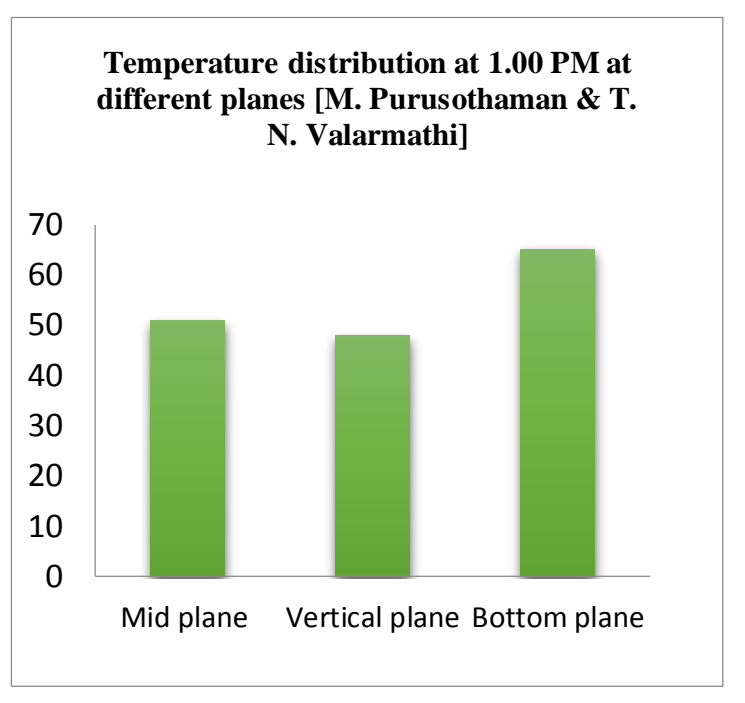

Figure 3 Temperature distribution at 1.00 PM at different planes [M. Purusothaman \& T. N. Valarmathi] 


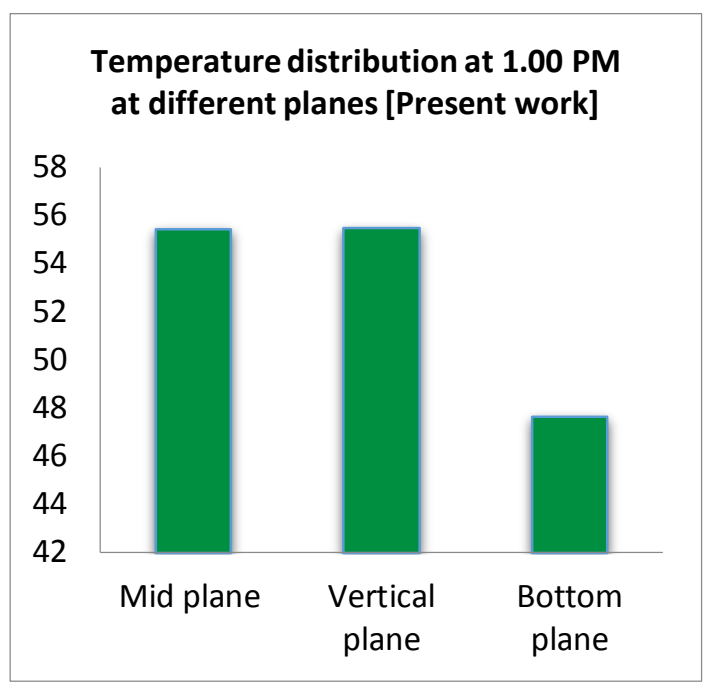

Figure 4 Temperature distribution at 1.00 PM at different planes [Present work]

\section{CFD analysis on greenhouse solar dryer for design-2:}

The temperature contour diagram at mid-plane at 10 a.m. shows a range of $29.85 \mathrm{oC}$ to $55.64 \mathrm{oC}$. As shown in figure 5 , the maximum temperature at the mid surface is $55.64 \mathrm{oC}$. The temperature contour diagram in the vertical plane at 10 a.m. shows a range of $29.85 \mathrm{oC}$ to $55.64 \mathrm{oC}$. At the vertical surface, the maximum temperature is $55.64 \mathrm{oC}$. The temperature contour diagram at the bottom plane at 10 a.m. shows a range of $30.28 \mathrm{oC}$ to $42.71 \mathrm{oC}$. $42.71 \mathrm{oC}$ is the maximum temperature at the bottom surface.

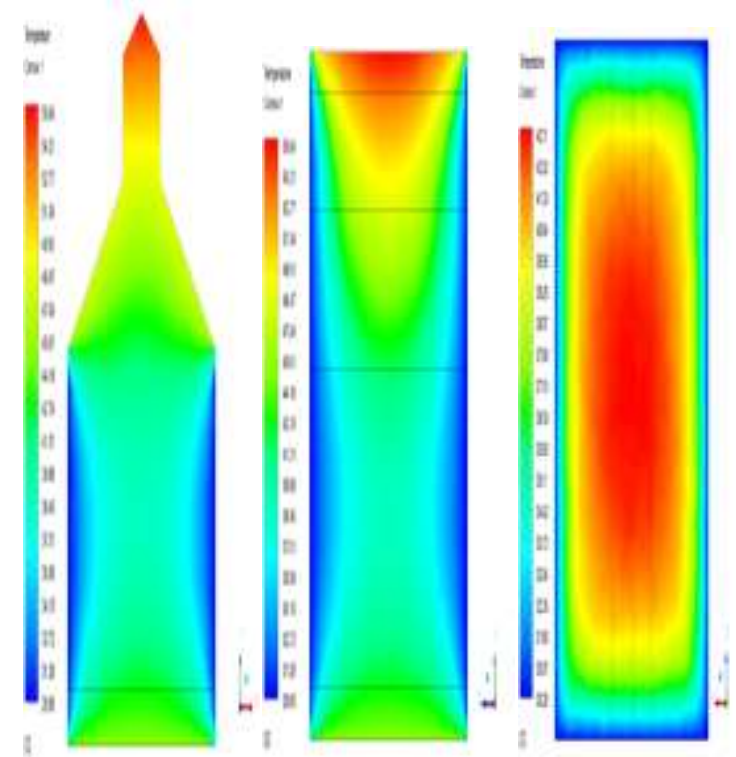

Figure 5: Temperature contour inside the solar dryer for design-2at $10 \mathrm{AM}$ on mid plane, vertical plane and bottom plane

It is observed from the temperature contour diagram at mid plane at 2.00 PM ranging from $29.85 \mathrm{oC}$ to $62.28 \mathrm{oC}$. The maximum temperature at the mid surface is $62.28 \mathrm{oC}$ as shown in figure no. 5.14 It is observed from the temperature contour diagram at vertical plane at $2.00 \mathrm{PM}$ ranging from $29.850 \mathrm{C}$ to $62.28 \mathrm{oC}$. The maximum temperature at the mid surface is $62.28 \mathrm{oC}$ It is observed from the temperature contour diagram at bottom plane at 2.00 PM ranging from $30.28 \mathrm{oC}$ to $42.90 \mathrm{oC}$. The maximum temperature at the bottom surface is $42.90 \mathrm{oC}$.

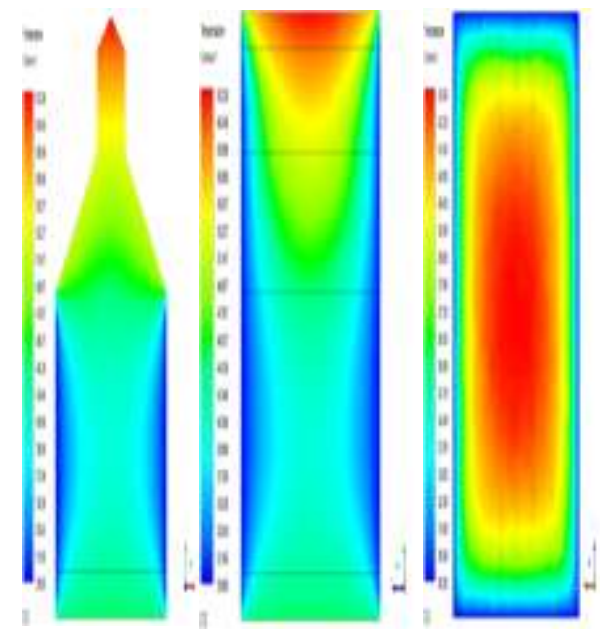

Figure 6: Temperature contour inside the solar dryer for design-2at 2.00 PM on mid plane,vertical plane and bottom plane

It is observed from the temperature contour diagram at mid plane at 5.00 PM ranging from $29.85 \mathrm{oC}$ to $56.77 \mathrm{oC}$. The maximum temperature at the mid surface is $56.77 \mathrm{oC}$ as shown in figure no. 5.17. It is observed from the temperature contour diagram at vertical plane at 5.00 PM ranging from $29.850 \mathrm{C}$ to $56.77 \mathrm{oC}$. The maximum temperature at the mid surface is $56.77 \mathrm{oC}$ It is observed from the temperature contour diagram at bottom plane at 5.00 PM ranging from $30.28 \mathrm{oC}$ to $42.74 \mathrm{oC}$. The maximum temperature at the bottom surface is $42.74 \mathrm{oC}$

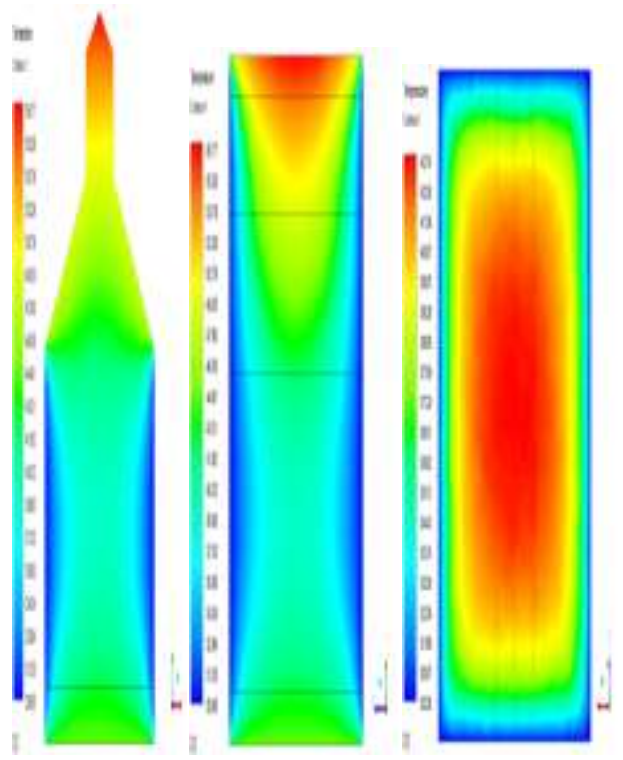

Figure 7: Temperature contour inside the solar dryer for design-2at 5.00 PM on mid plane, vertical plane and bottom plane

CFD analysis on greenhouse solar dryer for design-3: 
It is observed from the temperature contour diagram at mid plane at $10.00 \mathrm{AM}$ ranging from $29.85 \mathrm{oC}$ to $59.23 \mathrm{oC}$. The maximum temperature at the mid surface is $59.23 \mathrm{oC}$ as shown in figure no. $5.18 \mathrm{It}$ is observed from the temperature contour diagram at vertical plane at $10.00 \mathrm{AM}$ ranging from $29.85 \mathrm{oC}$ to $58.30 \mathrm{oC}$. The maximum temperature at the mid surface is $58.30 \mathrm{oC}$ It is observed from the temperature contour diagram at bottom plane at $10.00 \mathrm{AM}$ ranging from $32.62 \mathrm{oC}$ to $42.87 \mathrm{oC}$. The maximum temperature at the bottom surface is $42.87 \mathrm{oC}$

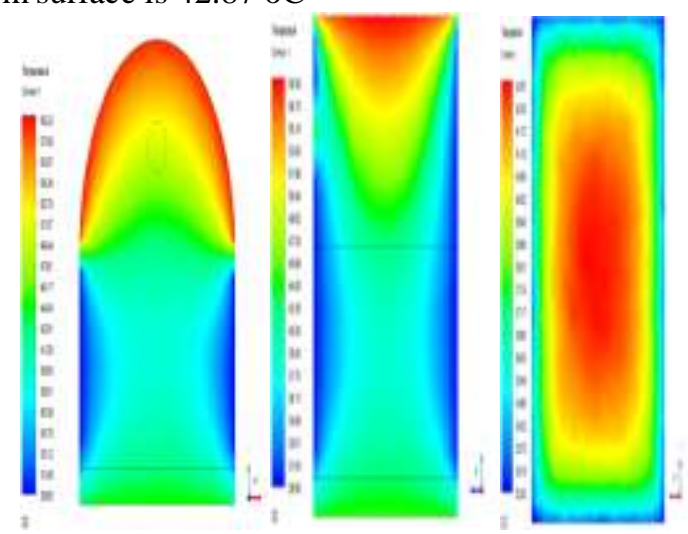

Figure 8: Temperature contour inside the solar dryer for design-3 at 10.00 AM on mid plane, vertical plane and bottom plane

It is observed from the temperature contour diagram at mid plane at 2.00 PM ranging from $29.85 \mathrm{oC}$ to $64.26 \mathrm{oC}$. The maximum temperature at the mid surface is $64.26 \mathrm{oC}$ as shown in figure no. 5.22. It is observed from the temperature contour diagram at vertical plane at 2.00 PM ranging from $29.85 \mathrm{oC}$ to $63.12 \mathrm{oC}$. The maximum temperature at the mid surface is $63.12 \mathrm{oC}$ It is observed from the temperature contour diagram at bottom plane at $2.00 \mathrm{PM}$ ranging from $32.62 \mathrm{oC}$ to $42.99 \mathrm{oC}$. The maximum temperature at the bottom surface is $42.99 \mathrm{oC}$

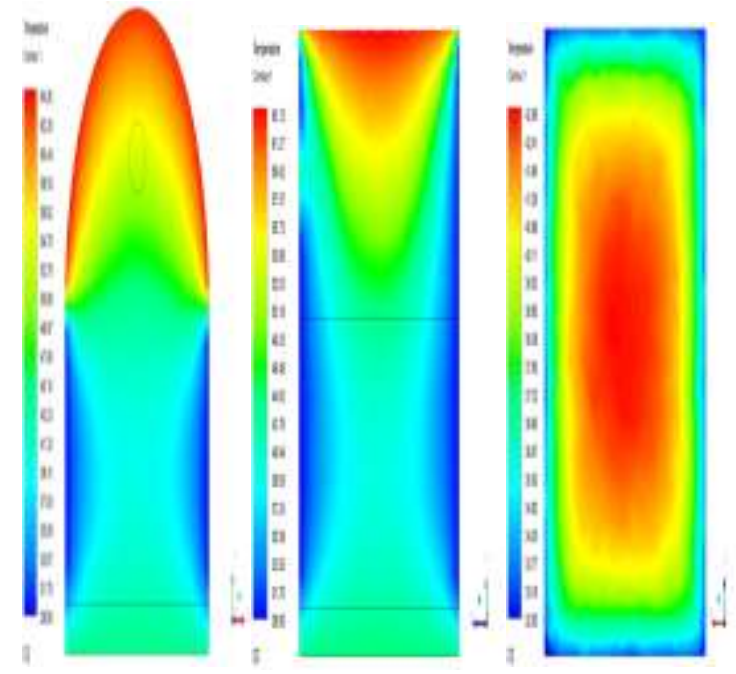

Figure 9: Temperature contour inside the solar dryer for design-3 at 2.00 PM on mid plane, vertical plane and bottom plane

It is observed from the temperature contour diagram at mid plane at $10.00 \mathrm{AM}$ ranging from $29.85 \mathrm{oC}$ to $73.77 \mathrm{oC}$. The maximum temperature at the mid surface is $73.77 \mathrm{oC}$ as shown in figure no. 5.26. It is observed from the temperature contour diagram at vertical plane at 10.00 AM ranging from $29.85 \mathrm{oC}$ to $73.82 \mathrm{oC}$. The maximum temperature at the mid surface is $73.82 \mathrm{oC}$ It is observed from the temperature contour diagram at bottom plane at $10.00 \mathrm{AM}$ ranging from $30.25 \mathrm{oC}$ to $66.04 \mathrm{oC}$. The maximum temperature at the bottom surface is $66.04 \mathrm{oC}$.

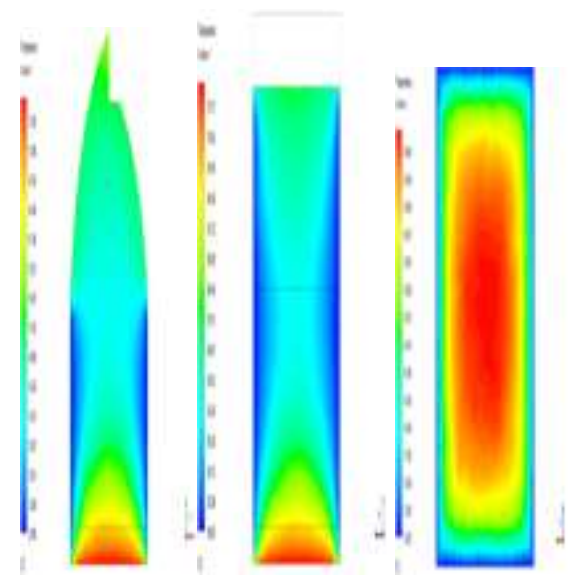

Figure 10: Temperature contour inside the solar dryer for design-4 at 10.00 AM on mid plane,vertical plane and bottom plane

It is observed from the temperature contour diagram at mid plane at 2.00 PM ranging from $29.85 \mathrm{oC}$ to $77.27 \mathrm{oC}$. The maximum temperature at the mid surface is $77.27 \mathrm{oC}$ as shown in figure no. 5.30. It is observed from the temperature contour diagram at vertical plane at 2.00 PM ranging from $29.85 \mathrm{oC}$ to $76.14 \mathrm{oC}$. The maximum temperature at the mid surface is $76.14 \mathrm{oC}$ It is observed from the temperature contour diagram at bottom plane at 2.00 PM ranging from $30.25 \mathrm{oC}$ to $68.08 \mathrm{oC}$. The maximum temperature at the bottom surface is $68.08 \mathrm{oC}$.
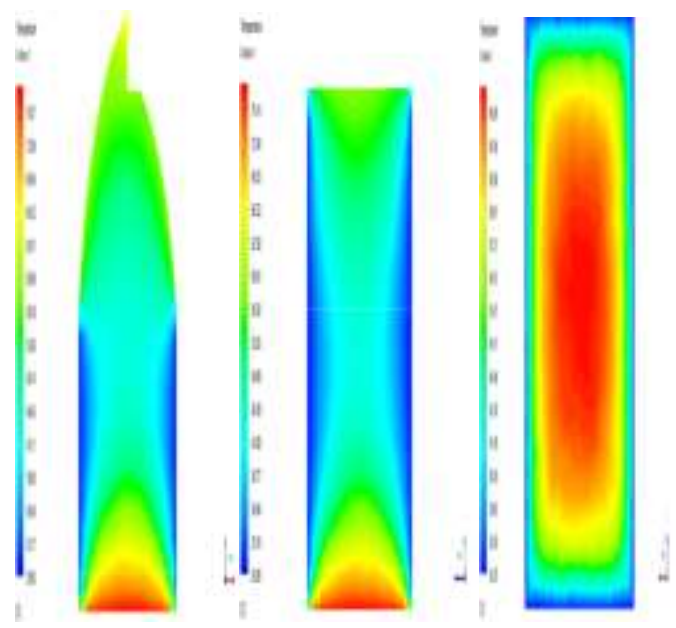

Figure 11: Temperature contour inside the solar dryer for design-4 at 2.00 PM on mid plane,vertical plane and bottom plane

It is observed from the temperature contour diagram at mid plane at 5.00 PM ranging from $29.85 \mathrm{oC}$ to $72.48 \mathrm{oC}$. The 
maximum temperature at the mid surface is $72.48 \mathrm{oC}$ as shown in figure no. 5.33. It is observed from the temperature contour diagram at vertical plane at 5.00 PM ranging from $29.85 \mathrm{oC}$ to $72.35 \mathrm{oC}$. The maximum temperature at the mid surface is $72.35 \mathrm{oC}$ It is observed from the temperature contour diagram at bottom plane at 5.00 PM ranging from $30.25 \mathrm{oC}$ to $64.81 \mathrm{oC}$. The maximum temperature at the bottom surface is $84.81 \mathrm{oC}$.

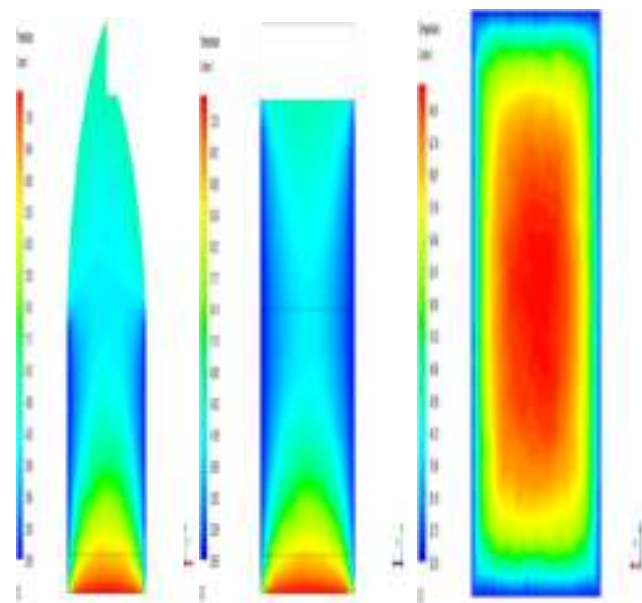

Figure 12: Temperature contour inside the solar dryer for design-4 at 5.00 PM on mid plane, vertical plane and bottom vertical plane

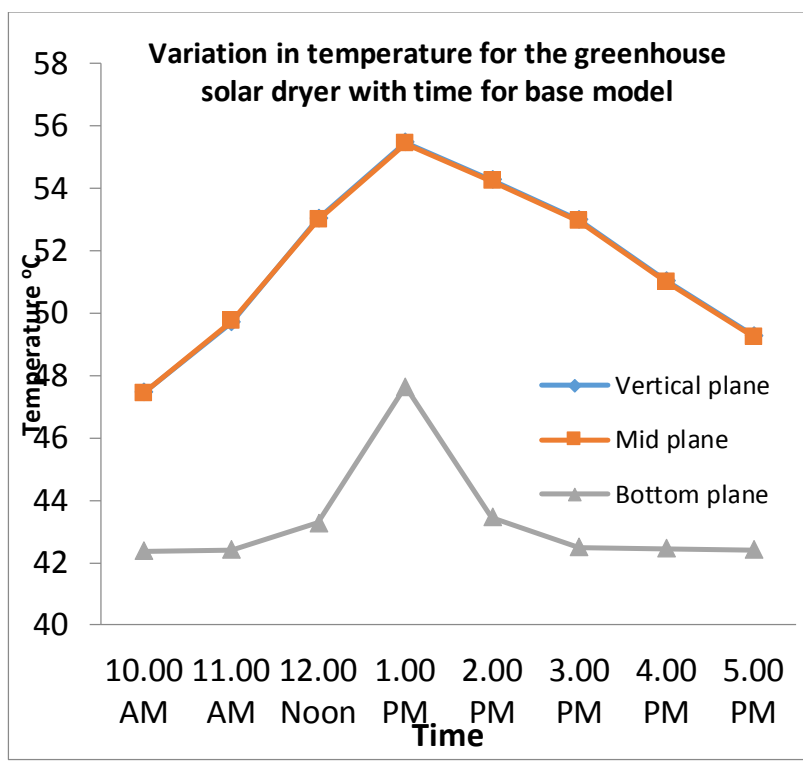

The graphs given above and below shows the temperature variation in different time periods for the solar dryer driven by green house for the base model, proposed design-2,3 and 4.
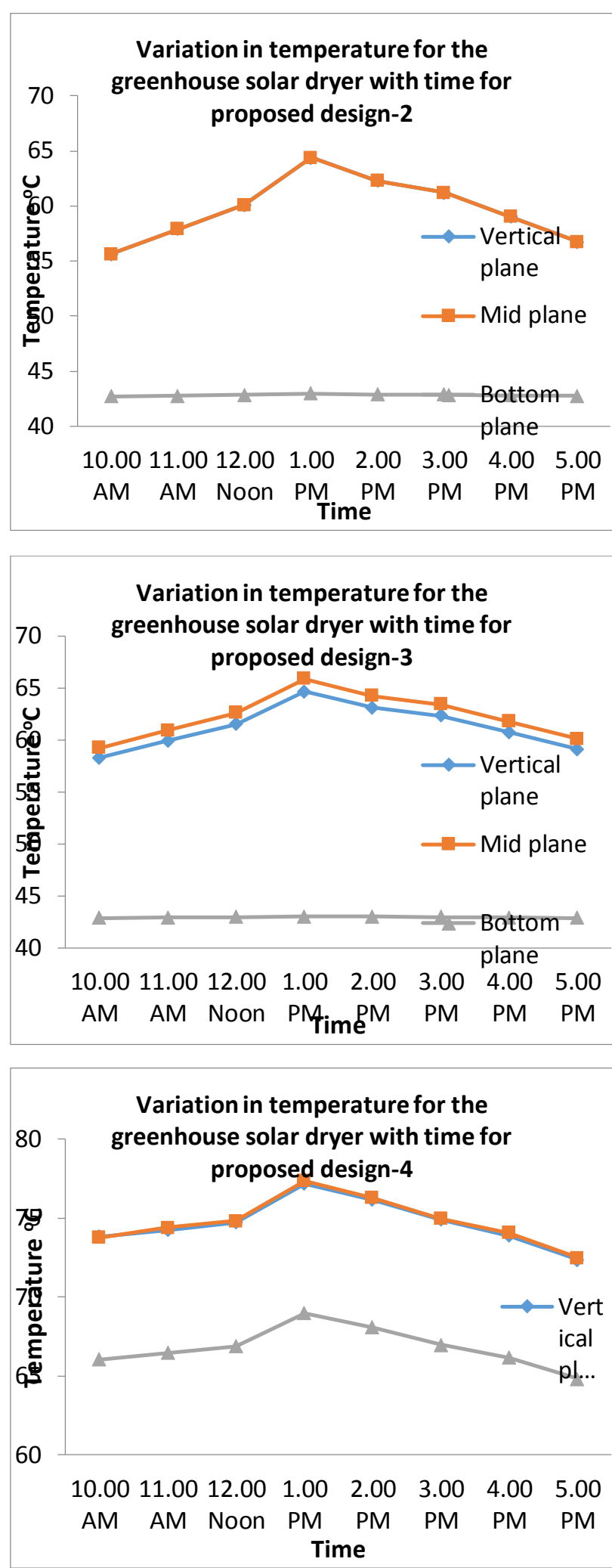

From the above table it can be seen that the temperature between $1 \mathrm{p} . \mathrm{m}$ to 2 p.m is high as compared to 10 a.m and 5 p.m in all the three planes i.e; vertical, bottom and mid plane.

\section{CONCLUSION}

For the temperature differences within the dryer, a computational fluid dynamics assessment was conducted on 
4 distinct designs of greenhouse solar dryers. To get the best results, this testing is conducted on the warmest day of the year (May 21st). For a deeper comprehension of temperature profiles, three different planes were considered: vertical, mid, and bottom. The greenhouse solar dryer's geometrical parameters are $1.2 \times 1.2 \times 1.5 \mathrm{~m}, 0.65 \mathrm{~m}$ for the height of the side walls from the ground, $0.01 \mathrm{~m}$ for the inlet gap on four sides of the dryer, and $0.15 \mathrm{~m}$ for the mass flow rate of the fan provision diameter. The roof is covered with a polycarbonate sheet, which allows infrared radiation to enter the dryer. The radiation model is applied to the location of Bhopal, which is located at $23.25^{\circ} \mathrm{N}$ and $77.33^{\circ} \mathrm{E}$, respectively.

According to the above CFD analysis for various greenhouse solar dryer designs, the maximum temperature of $77.36 \mathrm{oC}$ was observed at $01 \mathrm{pm}$ on the mid plane for design-4, which was 32.95 percent higher than the base model, 18.26 percent higher than design-2, and 16.01 percent higher than design-3. As a result, design-4 of the green - house solar dryer outperforms all other proposed designs in terms of heating performance.

\section{REFERENCE}

[1] D. Jagadeesh, M. Vivekanandan, A. Natarajan, S. Chandrasekar "Experimental conditions to identify the ideal shape of dryer investigation of six shapes of solar greenhouse dryer in no load" Materials Today: Proceedings, Accepted 13 May 2020. https://doi.org/10.1016/j.matpr.2020.05.386.

[2] Masnaji R. Nukulwar\&Vinod B. Tungikar "A review on performance evaluation of solar dryer and its material for drying agricultural products" Materials Today: Proceedings, Accepted 12 August 2020. https://doi.org/10.1016/j.matpr.2020.08.354.

[3] Lakshmi DVN, Muthukumar P, Nayak PK, Experimental Investigations on Active Solar Dryers Integrated with Thermal Storage for Drying of Black Pepper, Renewable Energy. https://doi.org/10.1016/j.renene.2020.11.144.

[4] V.P. Sethi\&MankaranDhiman "Design, space optimization and modelling of solar-cum-biomass hybrid greenhouse crop dryer using flue gas heat transfer pipe network" Solar Energy 206 (2020) 120-135.

https://doi.org/10.1016/j.solener.2020.06.006.

[5] Akhilesh Singh, Jahar Sarkar \&RashmiRekhaSahoo "Experimental performance analysis of novel indirect-expansion solarinfrared assisted heat pump dryer for agricultural products" Solar Energy 206 (2020) 907-917. https://doi.org/10.1016/j.solener.2020.06.065.

[6] ZakariaAlimohammadi, HadiSamimiAkhijahani\&Payman Salami "Thermal analysis of a solar dryer equipped with PTSC and PCM using experimental and numerical methods" Solar Energy 201 (2020) 157-177. https://doi.org/10.1016/j.solener.2020.02.079.

[7] Adnan Sozen at el. " Thermal performance enhancement of tube-type alternative indirect solar dryer with iron mesh modification" Solar Energy 207 (2020) 1269-1281. https://doi.org/10.1016/j.solener.2020.07.072.

[8] Saloni Spall \&V.P. Sethi "Design, modeling and analysis of efficient multi-rack tray solar cabinet dryer coupled with north wall reflector" Solar Energy $211 \quad$ (2020) 908-919. https://doi.org/10.1016/j.solener.2020.10.012.

[9] Y. Mohana at el. "Solar dryers for food applications: Concepts, designs, and recent advances" Solar Energy $208 \quad$ (2020) 321-344. https://doi.org/10.1016/j.solener.2020.07.098.

[10] Bilal Lamrani\&AbdeslamDraoui "Modelling and simulation of a hybrid solar-electrical dryer of wood integrated with latent heat thermal energy storage system" Thermal Science and Engineering Progress $18 \quad$ (2020) 100545. https://doi.org/10.1016/j.tsep.2020.100545. 